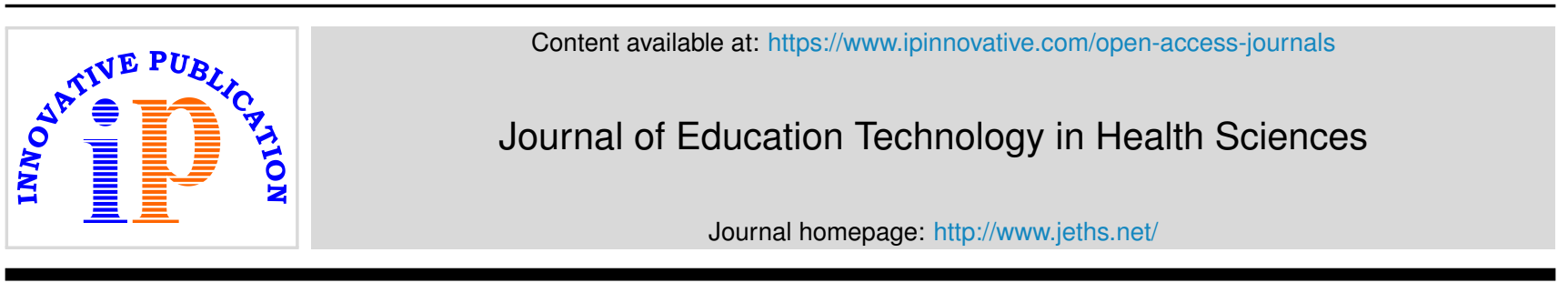

Original Research Article

\title{
Assessment on prevalence and its factors on phantom vibration syndrome among UG and PG students in selected colleges
}

\author{
Sunitha V' ${ }^{\mathbf{1}}$, R Rajesh ${ }^{2} *$, Jairakini Aruna ${ }^{2}$ \\ ${ }^{1}$ Dept. of Psychiatric Nursing, Sri Vishnu College of Nursing, Kolar, Karnataka, India \\ ${ }^{2}$ Dept. of Psychiatric Nursing, Sri Devaraj URS College of Nursing, Tamaka, Karnataka, India
}

\section{A R T I C L E I N F O}

\section{Article history:}

Received 07-12-2020

Accepted 28-12-2020

Available online 09-02-2021

\section{Keywords:}

Phantom vibration syndrome

Students

Smartphone addiction

\begin{abstract}
A B S T R A C T
Background: The phantom vibration syndrome occurs when a person thinks neither his or her phone is ringing or vibrating from a text message when it actually is not. As a society increasingly dependent on mobile devices, the phantom vibrate easily becomes a phenomenon of worry for mobile users.

Aim: To estimate the prevalence and its factors on phantom vibration syndrome.

Materials and Methods: A non-experimental study with comparative survey research design was developed. The study was conducted in Government First Grade PU College at Kolar. Non-probability convenient sampling technique was used to select the samples of 200 (100 UG, 100 PG) who fulfills the selection criteria. A checklist on phantom vibration syndrome with 15 items and questionnaire on assessing the factors influencing on phantom vibration syndrome with 11 items were used to collect the data from the samples through self-administered method. Descriptive and inferential statistics was used for analyzing the data.

Results: Majority of the students in UG 75\% were less than 20 years and 95\% were between 21-25 years with PG students. Regarding Gender 95\% was male in UG and 44\% were female in PG with $56 \%$ male. The findings of the data on prevalence showed that $71 \%$ of the UG students experienced phantom vibration syndrome and $29 \%$ of the UG students experienced some characteristics associated with phantom vibration syndrome, whereas among the PG students $50 \%$ reported as experienced with phantom vibration syndrome and remaining 50\% does not experience any symptoms associated with phantom vibration syndrome. Related to the factors influencing phantom vibration syndrome, $78 \%$ of the UG students reported that they keep their mobile phone in jean front pocket, $44 \%$ of the PG students said they place it in handbags /others. 57\% of the UG students used to check their phone for more than 20 times in a day where as 53\% of the PG students used to check for 10-20 times in a day. Both UG and PG students said that they feel the false vibration of ringing of their mobile phone during driving, sitting and engaged with any other activities were $42 \%$ and $47 \%$ respectively.

Conclusion: The findings of the study on phantom vibration syndrome among the students appear to reveal something about the use of contemporary technology in our day to day life and its addiction. So it is a warning sign that too much attachment and abusers to the mobile devices may have an impact on the health status and their behavior.

(C) This is an open access article distributed under the terms of the Creative Commons Attribution License (https://creativecommons.org/licenses/by/4.0/) which permits unrestricted use, distribution, and reproduction in any medium, provided the original author and source are credited.
\end{abstract}

\section{Introduction}

The phantom vibration syndrome occurs when a person thinks neither his or her phone is ringing or vibrating from a text message when it actually is not. ${ }^{1}$ As a society

\footnotetext{
* Corresponding author.

E-mail address: rajinirajesh007@gmail.com (R. Rajesh).
}

increasingly dependent on mobile devices, the phantom vibrate easily becomes a phenomenon of worry for mobile users. $^{2}$

In 2003 an article entitled "Phantom Vibration Syndrome" published in the New Pittsburgh Courier, written under a pen name of columnist Robert D. Jones 
states that our mind or body tell us the imaginary vibrations belts, pockets and even purses which may be result of physical nerve damage or a mental health issue or both. Phantom ringing syndrome is an intermittent perception that a mobile phone is ringing when actually it's not. It is a recent psychological phenomenon that has attracted the attention of medical community. ${ }^{3}$

Mobile phones become the base of communication technology today it becoming a basic need of all the people on earth with the advancement of cellular technology the problem associated with it also increases including the medical health problems, hypertension and certain psychological problems. ${ }^{4}$

\subsection{Need for the study}

New technology is a wonderful thing, but the more reliant we become to it, the more negatively we will be affected by it. Smart phones uses are constantly connected to their work, and the world around them which leads to anxiety which in turn cause dopamine imbalance leading to phantom vibration syndrome. ${ }^{5}$

As cell phones become increasingly in commonplace, questions are raised about how they may influence our everyday lives. One phenomenon that seems to speak to such questions is called' phantom vibration syndrome". This refers to when a user, whose phone is set to vibrate if an incoming call or text is received, experiences the phone to vibrate when in fact it was not vibrating at all. That is, this refers to a hallucination in which users perceive an inert phone to vibrate, believing that they are receiving a call or text message. What makes phantom vibrations interesting is their remarkable prevalence. In a study of undergraduates, almost $90 \%$ are found to have experienced phantom phone vibrations. Study of hospital workers found that nearly $70 \%$ has experienced this hallucination. ${ }^{6}$

\subsection{Statement of the problem}

"A comparative study to assess the Prevalence and its factors on Phantom vibration syndrome among UG and PG students in selected college's at Kolar, with a view to develop an Information booklet on Phantom vibration syndrome".

\subsection{Objectives}

1. To estimate the prevalence on phantom vibration syndrome among UG and PG students in selected colleges.

2. To find out the factors on phantom vibration syndrome among UG and PG students in selected colleges.

3. To determine the association between the prevalence of phantom vibration syndrome with selected sociodemographic variables of UG and PG students.

4. To determine the association between selected factors of phantom vibration syndrome with selected socio- demographic variables of UG and PG students.

\subsection{Hypothesis}

1. Ho ${ }_{1}$ - There is no statistically significant association between the prevalence of phantom vibration syndrome with selected socio- demographic variables of UG and PG students.

2. $\mathrm{Ho}_{2}-$ There is no statistically significant association between selected factors on phantom vibration syndrome with selected socio-demographic variables among UG and PG students.

3. $\mathrm{Ho}_{3}-$ There is no statistically significant difference between the prevalence score of phantom vibration syndrome among UG and PG students.

\subsection{Assumptions}

1. Experience of phantom vibration syndrome may be varying between UG and PG students.

2. Students of Degree College may have over involvement in one's cell phone usage.

3. Information booklet may help the students in knowing some information on phantom vibration syndrome.

\section{Materials and methods}

A descriptive survey research approach with nonexperimental comparative research design was adopted. The study was conducted on UG and PG students in Government first grade college at Kolar. The samples were selected by using non-probability convenient sampling technique with the sample size of 200 students (100 UG/100 PG) studying in science and commerce group who fulfills the selection criteria with the extension of support from their respective teachers. A checklist on phantom vibration syndrome with 15 items and questionnaire on assessing the factors influencing on phantom vibration syndrome with 11 items were used to collect the data from the samples through self-administered method. The following tools were used to collected data.

1. Tool -1: Socio - demographic profile.

2. Tool -2: Assessment of Prevalence on phantom vibration syndrome.

3. Tool -3: Assessing the factors influencing on phantom vibration syndrome.

Tool 1: Socio - demographic profile which include Age (in years), Gender, Area of residence, Family income per month (in rupees), Type of family, marital status, Educational status, Religion, Year of studying, Type of phone.

Tool 2: It consists of 15 items in a form of checklist with YES or NO options of Prevalence on phantom vibration syndrome.

Interpretation: scoring, if subject responses YES (1) and NO (0) were awarded to correct and wrong responses 
respectively. The maximum score was 15 , in which it is categorized as following,

1. $0-8$ : Not experienced PVS (absent)

2. 9 - 15: Experienced PVS (present)

Tool 3: It consists of 11 items in a form of multiple choice questions with on assessing the factors influencing on phantom vibration syndrome.

Formal permission was obtained from the institutional ethics committee of the institution and concerned approval was taken from the authority of the college, the investigator explained the purpose of the study to the students as well as to their teachers and obtained written informed consent from the subjects. With the support of the teachers the students were screened by using the tool on phantom vibration syndrome among the students who were interested to participate in the study according to the investigator convenient until the desired sample size was reached. Each study subject's information was collected on one-toone basis through self-administered method. Confidentiality and anonymity was maintained during the process of data collection. Later the data was coded and preceded for statistical analysis by using descriptive and inferential statistics.

\section{Results}

\subsection{Socio-demographic Variables}

1. Age: $75 \%$ (75) of UG students were in the age group of less than 20 years, $25 \%$ (25) were in the age group of 21-25 years. Among PG students $95 \%$ (95) were in the age group of $21-25$ years and $05 \%(05)$ were in the age 26-30 years.

2. Gender: $95 \%$ (95) of UG students were males and $5 \%$ (5) were females. And among PG students56\% (56) were males and 44\% (44) were females.

3. Area of residence: $18 \%$ (18) of UG students were from urban area and $82 \%(82)$ were from rural area. And among PG students 15\% (15) were from urban area and $85 \%(85)$ were from rural area.

4. Type of the family: $56 \%$ (56) of UG students are from nuclear family and 44\% (44) were from joint family. And among PG students 61\% (61) are from nuclear family and $39 \%$ (39) were from joint family.

5. Marital status: $03 \%$ (03) of UG students were married, 97\% (97) of students were unmarried. And among PG students 06\% (06) were married, 94\% (94) of students were unmarried.

6. Educational status: Among UG students they are doing courses like20\% (20) were doing BA, 35\% (35) were BBM, and $45 \%$ (45) were studying in BCOM. And among PG students 45\% (45) were doing MA in Kannada, 30\% (30) were MA in sociology, 25\% (25) were studying MA in political.
7. Religion: $89 \%$ (89) of UG students were Hindus, $11 \%$ (11) were Muslims. And among PG students 95\% (95) were Hindus, 04\% (04) were Muslims, 01\% (01) found to be Christian.

8. Year of studying: $05 \%(05)$ of UG students were in $1^{s t}$ year, $95 \%$ (95) were in $2^{\text {nd }}$ year and nobody was in $3^{r d}$ year. And among PG students $64 \%$ (64) were in $1^{\text {st }}$ year, $36 \%$ (36) were in 2 nd year, and nobody were in 3 rd year.

9. Type of phone using: $50 \%$ (50) of UG students were using simple mobile phone, 50\% (50) were using smart phone. And among PG students $40 \%$ (40) were using simple mobile phone, 60\% (60) were using smart phone.

Table 1 discussed on the prevalence on phantom vibration syndrome Among UG students 29\% (29) had experienced, and 71\% (71) had not experienced PVS. Whereas Among PG students 50\% (50) had experienced, and $50 \%$ (50) had not experienced PVS.

Table 2 discussed on the comparison of prevalence score on PVS among UG \& PG students. The mean score of UG students is 6.89 with standard deviation 2.57 . Where as in PG students the mean score is 8.23 with standard deviation 3.05; on comparison of the ' $\mathrm{t}$ ' value is the 5.82 for $\mathrm{df}=198$ which shows statistically significant at $\mathrm{P}<0.05$.

\section{Discussion}

The present study findings was supported by a similar study conducted by Goyal AK (2015) with the study on The survey of 300 postgraduate students belonging to different field of specialization was conducted at Kurukshetra University. The findings revealed that $74 \%$ of students were found to have both Phantom vibrations and ringing syndrome. Whereas $17 \%$ of students felt Phantom vibration exclusively and 4\% students face only Phantom ringing syndrome. Both the syndrome occurs more fervent in students who kept their mobile phone in shirt or jean pocket than to who kept mobile in handbag. $75 \%$ of students felt vibration or ringing even when the phone is switched off or phone was not in their pocket. Also the frequency of both the syndrome is directly proportional to the duration of mobile phone use and person emotional behaviour. Although most of students agree that the Phantom syndrome did not bother them but some students deals with anxiety when they feel symptoms associated with Phantom syndrome. ${ }^{3}$

Another similar study by Michael B Rothberg, Reva Kleppel (2010) To describe the prevalence of and risk factors for experiencing "phantom vibrations," the sensory hallucination sometimes experienced by people carrying pagers or cell phones when the device is not vibrating. With the Participants 176 medical staff who responded to questionnaire $(76 \%$ of the 232 people invited) Measurements electronic survey consisting of 
Table 1: Frequency and percentages distribution of prevalence on phantom vibration syndrome among UG and PG students. (N=200 $(\mathrm{UG}=100 / \mathrm{PG}=100))$

\begin{tabular}{|c|c|c|c|c|c|}
\hline \multirow{2}{*}{ S.No } & \multirow{2}{*}{$\begin{array}{l}\text { Study variable (phantom } \\
\text { vibration syndrome) }\end{array}$} & \multicolumn{2}{|c|}{ UG students $\left(\mathrm{n}_{1}=\mathbf{1 0 0}\right)$} & \multicolumn{2}{|c|}{ PG students $\left(\mathrm{n}_{2}=100\right)$} \\
\hline & & Frequency (f) & Percentage $(\%)$ & Frequency (f) & Percentage $(\%)$ \\
\hline 01 & $\begin{array}{l}\text { Students who Experienced } \\
\text { PVS (present) } \geq 8\end{array}$ & 29 & 29 & 50 & 50 \\
\hline 02 & $\begin{array}{l}\text { Students who are Not } \\
\text { Experienced PVS (absent) } \leq 8\end{array}$ & 71 & 71 & 50 & 50 \\
\hline
\end{tabular}

Table 2: Comparison of prevalence score on phantom vibration syndrome among UG students and PG students

\begin{tabular}{llcccccc}
\hline S. No & $\begin{array}{c}\text { Prevalence score on } \\
\text { PVS }\end{array}$ & Mean & $\begin{array}{c}\text { Standard } \\
\text { Deviation }\end{array}$ & 't' value & df & ' $\mathbf{p}$ ' Value & Inference \\
01 & UG students $\left(\mathrm{n}_{1}=100\right)$ & 6.89 & 2.572 & 5.82 & 198 & $<0.05$ & $*$ SS statistically \\
significant
\end{tabular}

(SS- statistically significant at $\mathrm{p}<0.05$ )

17 questions about demographics, device use, phantom vibrations experienced, and attempts to stop them. The findings revealed that of the 169 participants who answered the question, $115(68 \%$, 95\% confidence interval $61 \%$ to $75 \%$ ) reported having experienced phantom vibrations. Most (68/112) who experienced phantom vibrations did so after carrying the device between 1 month and 1 year, and $13 \%$ experienced them daily. Four factors were independently associated with phantom vibrations: occupation (resident $\mathrm{v}$ attending physician, prevalence ratio $1.47,95 \%$ confidence interval 1.10 to 1.97 ), device location (breast pocket $\mathrm{v}$ belt, prevalence ratio $1.66,1.29$ to 2.14), hours carried (per 6 hour increment, prevalence ratio 1.30, 1.07 to 1.58 ), and more frequent use in vibrate mode (per frequency category, prevalence ratio $1.18,1.03$ to 1.34). Of those who experienced phantom vibrations, 43 (39\%, $30 \%$ to $48 \%$ ) were able to stop them. Strategies for stopping phantom vibrations included taking the device off vibrate mode, changing the location of the device, and using a different device (success rates $75 \%$ v $63 \%$ v $50 \%$, respectively, $\mathrm{P}=0.217$ ). However, $39 \%$ (30\% to $49 \%$ ) of respondents did not attempt any strategies.

\section{Implications}

1. The findings of the current study have certain implications, such as the need for intensive in-service training for college teachers on identification of students who are at risk for smart phone addiction and its impact on emotional aspects.

2. The importance of sensitizing teachers and parents through awareness programmes to deal with the children who are at risk of developing some psychological problems due to PhantomVibrationSyndrome.

3. The urgency of appointing specially trained professionals like counselors and special educators to work along with the teachers in colleges to identify the etiology and provide effective treatment when required..

4. Prospective studies are needed for better prediction on who will develop the phantom vibration syndrome and its prognosis.

\section{Limitations}

1. The present study is limited to only UG and PG students of Degree College on assessment of prevalence and its factors on phantom vibration syndrome.

2. The data are completely self-reported from the students.

3. It's just a preliminary study with small sample size on students, their impact on various aspects of day to day activities were not measured.

4. Convenient sampling technique was used due to time constraints and little lack of co-operation from the students.

\section{Conclusion}

The findings of the study on phantom vibration syndrome among the students appear to reveal something about the use of contemporary technology in our day to day life and its addiction. So it is a warning sign that too much attachment and abusers to the mobile devices may have an impact on the health status and their behavior.

\section{Acknowledgement}

The investigator express their gratitude to all the UG and PG Students for their complete support and co-operation for participating in the study with the short duration and also to the college authorities of Government first grade college Kolar for giving permission to conduct the study. 
Table 3: Frequency and percentages distribution of factors on Phantom vibration syndrome among UG students and PG students. $(\mathrm{N}=200)$

S.

No

Factors on phantom vibration syndrome

Where you keep your mobile phone

a) Shirt pocket

$01 \quad$ b) Jean front pocket

c) Jean back pocket

d) Handbag / Other

02 Approximately How much time you spent on your mobile phones in a day
a) $<3$ hour
b) 3-6 hours
c) 6-9 hours
d) $>9$ hours

03 Since how many years you are using mobile phone.
a) $<5$ yrs.
b) 5-10 years
c) $10-15$ years
d) $>15$ years

04 On an average how many calls you will get in a day?
a) $<5$ calls
b) $5-10$ calls
c) $10-15$ calls
d) $>15$ calls

05 For which purpose you used the mobile phone maximum.

a) Calls

b) Text message

c) Playing ride games

d) Others application

e) Mobile phone songs and videos

06 On an average how many messages you will get a day?
a) $<5$ messages
b) 6-10 messages
c) 10-15 messages
d) $>15$ messages

07 How many times you check your phone in a day?
a) $<10$ times
b) 10-20 times
c) $>20$ times

08 Which part of the day you use the mobile phone on maximum
a) Morning
b) Afternoon
c) Evening
d) Night

09 On an average for how many minutes you check the mobile phone
a) For every 5-10 mints
b) 15 mints
c) 30 mints
d) Every 1 hour

10 When you feel the false vibration?
a) While driving / travelling
b) While sitting
c) When engaged in any other activity
d) All of the above

11 How much you are a stable emotional person.
a) Emotionally weak
b) Emotionally strong
21
79

\begin{tabular}{|c|c|}
\hline UG stud & $\left(\mathrm{n}_{1}=\mathbf{1 0 0}\right)$ \\
\hline $\begin{array}{l}\text { requency } \\
\text { (f) }\end{array}$ & $\begin{array}{c}\text { Percentage } \\
(\%)\end{array}$ \\
\hline
\end{tabular}

(\%)

12

78

06

04

60

31

05

04

70

24

02

04

34

34

14

18

41

14

05

10

30

34

20

20

26

57

22

21

22

10

25

43

19

16

20

45

22

26

10

42

12
78
06
04

$\begin{array}{cc}\text { PG students }\left(\mathbf{n}_{2}=100\right) \\ \text { requency } & \text { Percentage } \\ (f) & (\%)\end{array}$

09

36

09

36

11

44

44

50

36

11

03

11
03

56

34

04

06

04
06

38

38

13

11

25

36

05

11

23

31

17

34

18

53

35

12

12

11

12

13

64

64

$\begin{array}{ll}34 & 34 \\ 20 & 20 \\ 14 & 14 \\ 32 & 32 \\ & \\ 13 & 13 \\ 28 & 28 \\ 12 & 12 \\ 47 & 47\end{array}$

34

20

14

32

13

28

12

47

$42 \quad 47$

$31 \quad 31$

$\begin{array}{ll}69 & 69\end{array}$ 


\section{Source of Funding}

None.

\section{Conflict of Interest}

None.

\section{References}

1. Yadav SK. Mobile Phone in Investigation, E-Forensics Magazine; 2013.

2. Rothberg MB, Arora A, Hermann J, Keppel R, Marie P, Visintainer P. Phantom vibration syndrome among medical staff: a cross sectional survey. 2010;341:c6914. do1:10.1136/bm].c6914.

3. Goyal AK. Studies on Phantom Vibration and Ringing Syndrome among Postgraduate Students. Indian J Comm Health. 2015;27(1):3540 .

4. Sarwar M, Soomro TR. Impact of Smartphone's on Society. Eur J Sci Res. 2013;98:216-26.

5. Shoukat S. Cell phone addiction and psychological and physiological health in adolescents. EXCLI J. 2019;18:47-50.
6. Drouin M, Kaiser DH, Miller DA. Phantom vibrations among undergraduates: Prevalence and associated psychological characteristics. Computers Human Behav. 2012;28(4):1490-6. doi:10.1016/1.chb.2012.03.013.

7. Brendag I. Scott A, Dilbert. 1996. Available from: Http;//Www. Nytimes.Com.

\section{Author biography}

Sunitha V, Lecture

R Rajesh, Professor

Jairakini Aruna, Professor

Cite this article: Sunitha V, Rajesh R, Aruna J. Assessment on prevalence and its factors on phantom vibration syndrome among UG and PG students in selected colleges. J Educ Technol Health Sci 2020;7(3):90-95. 